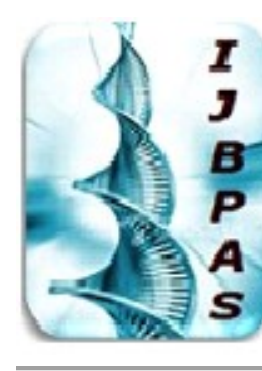

International Journal of Biology, Pharmacy and Allied Seiences (IJBPAS) 'A Bridge Betusen Caboratory and QRendo'

Www.ijbpas.com

\title{
SOLUBILITY AND DISSOLUTION ENHANCEMENT OF BCS CLASS II DRUG PIROXICAM BY SOLID DISPERSION
}

\section{SHAIKH SIRAJ N ${ }^{*}$, SIDDIQI HIFZURRAHMAN MD A ${ }^{2}$, KHAN GJ ${ }^{1}$, MAKRANI SI ${ }^{1}$, KHALIFA MAHMADASIF YUNUS ${ }^{1}$, SHAOOR AHMED $S^{3}$ AND JADHAV RL ${ }^{4}$}

1: Department of Pharmaceutics, Ali-Allana College of Pharmacy Akkalkuwa, Nandurbar, Maharashtra, India

2: Department of Pharmaceutics, Jamia College of Pharmacy Akkalkuwa, Nandurbar, Maharashtra, India

3: Shree Swami Samarth Ayurvedic Pharmacy (Allopathic division), Jalgaon, Maharashtra, India 4: Department of Pharmaceutical Chemistry, Gourishankar Institute of Pharmaceutical Education and Research, Limb, Satara, Maharashtra, India-415001

*Corresponding Author: E Mail: sirajsk1234@gmail.com

Received $18^{\text {th }}$ Jan. 2020; Revised $18^{\text {th }}$ Feb. 2020; Accepted $16^{\text {th }}$ March 2020; Available online $1^{\text {st }}$ June. 2020

https://doi.org/10.31032/IJBPAS/2020/9.9.5148

ABSTRACT

The Present study was conducted to improve solubility and dissolution of poor water soluble drug Piroxicam. In this research work, Piroxicam Solid Dispersion was prepared kneading method by using, Guar Gum as a carrier. Drug and carriers weight ratio were1:1 to 1:5. The properties of solid were evaluated using Fourier Transform Infra red (FTIR) Spectroscopy, differential scanning calorimetry (DSC), scanning electron microscopy (SEM), and solubility and dissolution studies. The FTIR Spectroscopy showed no chemical interaction between Piroxicam and carrier. DSC studies indicated their no change of melting point of Piroxicam in Solid Dispersion. SEM result showed that Piroxicam was dispersed and was present as amorphous state in the solid dispersions. Solubility of Solid dispersions was highest at Ratio 1:5 is $0.319 \pm 0.02 \mathrm{mg} / \mathrm{mL}$. The drug release data of solid dispersion revealed that formulation F5 exhibited more than $95 \%$ drug release after 60 min. Finally we conclude that the solubility \& 
dissolution enhancement is depend on nature and amount of the carrier and when increases the carrier increase the solubility of Piroxicam. Solid dispersion system of Piroxicam and carriers used could improve the solubility and dissolution rate of Piroxicam.

Keyword: Solid dispersion, Piroxicam kneading method, Guar Gum

\section{INTRODUCTION}

The poorly aqueous solubility of new chemical entities is increasingly posing a significant challenge in the development of the pharmaceutical industry ${ }^{1}$. The bioavailability of oral Dosage forms depends on the Solubility and dissolution rate of drug. Some techniques to enhance the solubility of poor water soluble drug such as solid dispersion, salt formation, micronization, $\mathrm{Co}$ crystallization, Co solvency method [1, 2]. The solid dispersion in which dispersion of one or more active ingredient in an inert carrier or matrix at solid state prepared by melting, Kneading, Solvent evaporation methods [3]. Solid dispersion in which a molecular dispersion of insoluble drug in a hydrophilic polymer/carrier at solid state. Solid dispersion technique is used in the pharmaceutical field to enhance the solubility and dissolution rate of poor water soluble drug. It has been widely used to improve the

MATERIAL AND METHODS

\section{Materials}

Piroxicam was obtained as a gift sample from Shree Swami Samarth Ayurvedic Pharmacy (Allopathic division) Jalgaon,Guar gum, oral absorption and bioavailability of BCS class II drug $[4,5]$.

Piroxicam belongs to the BCS Class II drugs mean low solubility and high permeability that's why the oral absorption of Piroxicamislimited.BCS class II drugs pose challenging problems in their pharmaceutical product development process because of their low solubility and dissolution rates. They require enhancement in solubility and dissolution rate in their formulation development especially solid dosage forms such as tablets and capsules. Several conventional methods and new emerging technologies have been developed for formulation development of BCS class II drugs [6].

The objectives of present research work are to enhance the solubility and dissolution of poor water soluble drug Piroxicam by preparing Solid dispersion.

Sodium Hydrogen Phosphate, Sodium Dihydrogen Phosphate, Ethanol were purchased from Research Lab Fine Chem Industries, Mumbai. 


\section{Methods}

\section{Drug \& DSC -Excipient Compatibility}

Study:FTIR \& DSC studies were conducted to know the compatibility between drug and excipients [7].

\section{Solid Dispersion Preparation by Kneading}

\section{Method [8, 9]}

Piroxicam Solid Dispersion System contains Guar Gum and Piroxicam were made with the following Ratio shown in Table 1. Drug + carrier is dissolved in methanol. Dissolved properly and triturate with the help of mortar pastel and Kneaded properly after then Dried at $45^{\circ} \mathrm{C}$ for $1 \mathrm{hr}$ in hot air oven and then pass through sieve no. 80. Finally collected the Solid Dispersion and the keep in desiccators for further study.

Table 1: Formulation of Solid Dispersion Batches

\begin{tabular}{|c|c|}
\hline Ratio & Guar gum (GG) \\
\hline $1: 1$ & Piroxicam + G G (100+100) \\
\hline $1: 2$ & Piroxicam + G G (100+200) \\
\hline $1: 3$ & Piroxicam + G G (100+300) \\
\hline $1: 4$ & Piroxicam + G G (100+400) \\
\hline $1: 5$ & Piroxicam + G G (100+500) \\
\hline
\end{tabular}

\section{Solubility Study [10, 11]}

Take an excess quantity of solid dispersion particle Dissolved in $25 \mathrm{ml}$ Phosphate buffer (pH 7.4) in $50 \mathrm{ml}$ glass vials fitted with screw capped. The vials are shaken for $2 \mathrm{hrs}$ on mechanical stirrer

after that the solution was filter through whatman filter paper and then drug concentration was determine through UV Spectrophotometer at $242 \mathrm{~nm}$.

Drug Content (assay) [12] 15 mg Piroxicam incorporated solid dispersion was weighed accurately and dissolved in $20 \mathrm{ml}$ methanol and volume make upto $100 \mathrm{ml}$ with 7.4 phosphate buffer. The solutions were filtered and take $1 \mathrm{ml}$ of above solution and diluted with upto $10 \mathrm{ml}$ with 7.4 phosphate buffer solution and drug content was determined at $242 \mathrm{~nm}$ by UV spectrophotometer after suitable dilution.

Scanning electron microscopy analysis (SEM) [13]

SEM study was performed to check out the surface morphology of the Piroxicam Solid Dispersion

In vitro Dissolution Study of Piroxicam Solid Dispersion $[14,15]$

Parameter

Condition

Temperature $37 \pm 0.5^{\circ} \mathrm{C}$

Dissolution media $7.4 \mathrm{pH}$ phosphate buffer

Volume of dissolution media $900 \mathrm{ml}$ Aliquot withdraw $5 \mathrm{ml}$

Aliquot replace $5 \mathrm{ml}$

Dissolution apparatus

Revolution per minute USP type II (paddle) 100 RPM

Sampling time intervals $10 \mathrm{~min}, 20 \mathrm{~min}, 30 \mathrm{~min}$, $40 \mathrm{~min}, 50 \mathrm{~min}, 60 \mathrm{~min}$.

\section{RESULTS AND DISCUSSIONS}

\section{FTIR Study}

FTIR analysis was performed to see the spectrum formed of Piroxicam Solid 
dispersion with selected natural carrier (Guar Gum) by kneading method with compared to the spectrum of pure Piroxicam. The result has show in (Figure 1). The principal absorption peaks of Piroxicam were observed at $625.92 \mathrm{~cm}^{-1}$ (S-Cstretch), $1149.16 \mathrm{~cm}^{-1}$ ( $\mathrm{S}=\mathrm{O}$ stretch), $1351.18 \mathrm{~cm}^{-1}(\mathrm{C}-\mathrm{H}$ stretch), $1729.24 \mathrm{~cm}^{-1}(\mathrm{C}=\mathrm{O}$ stretch $), 2758.30 \mathrm{~cm}^{-1}$ $\left(\mathrm{C}=\right.$ Cstretch), $3337.93 \mathrm{~cm}^{-1} \quad$ (O-Hstretch), $3392.90 \mathrm{~cm}^{-1}$ (N-Hstretch). So in spectra of Piroxicam solid dispersion the selected natural carrier suggest no interaction between the drug and the carrier Guar Gum.

\section{DSC Study}

DSC analysis is performed to see the melting point and interaction that occur between the Piroxicam and carrier (Guar Gum). Thermo gram is showed the temperature at endothermic peak of Piroxicam solid dispersion. Thermogram of Piroxicam showed the endothermic reaction that occurs at melting process exact peak at $200^{\circ \mathrm{C}}$ and it is a melting point of Piroxicam. The result has showed in (Figure 2).

\section{Solubility Result}

The highest solubility in the batch of Ratio 1:5 in Table $20.319 \pm 0.02(\mathrm{mg} / \mathrm{mL})$.

Solubility of solid dispersion of F5 batch at ratio of 1:5 $0.319 \pm 0.02(\mathrm{mg} / \mathrm{mL})$ Table 3.

\section{SEM Study}

The surface morphology of Piroxicam Solid Dispersion was observed by SEM. The result has been show in (Figure 3). In this picture of Piroxicam solid dispersion (GG Ratio 1:5) has show Piroxicam is dispersed in Natural carrier Guar gum. SEM result showed that Piroxicam was dispersed and was present as amorphous state in the solid dispersions.

\section{In vitro dissolution study result of Piroxicam Solid Dispersion batches}

The drug release data of solid dispersion revealed that formulation F5 exhibited more than $95 \%$ drug release after $60 \mathrm{~min}$ (Figure 4). 


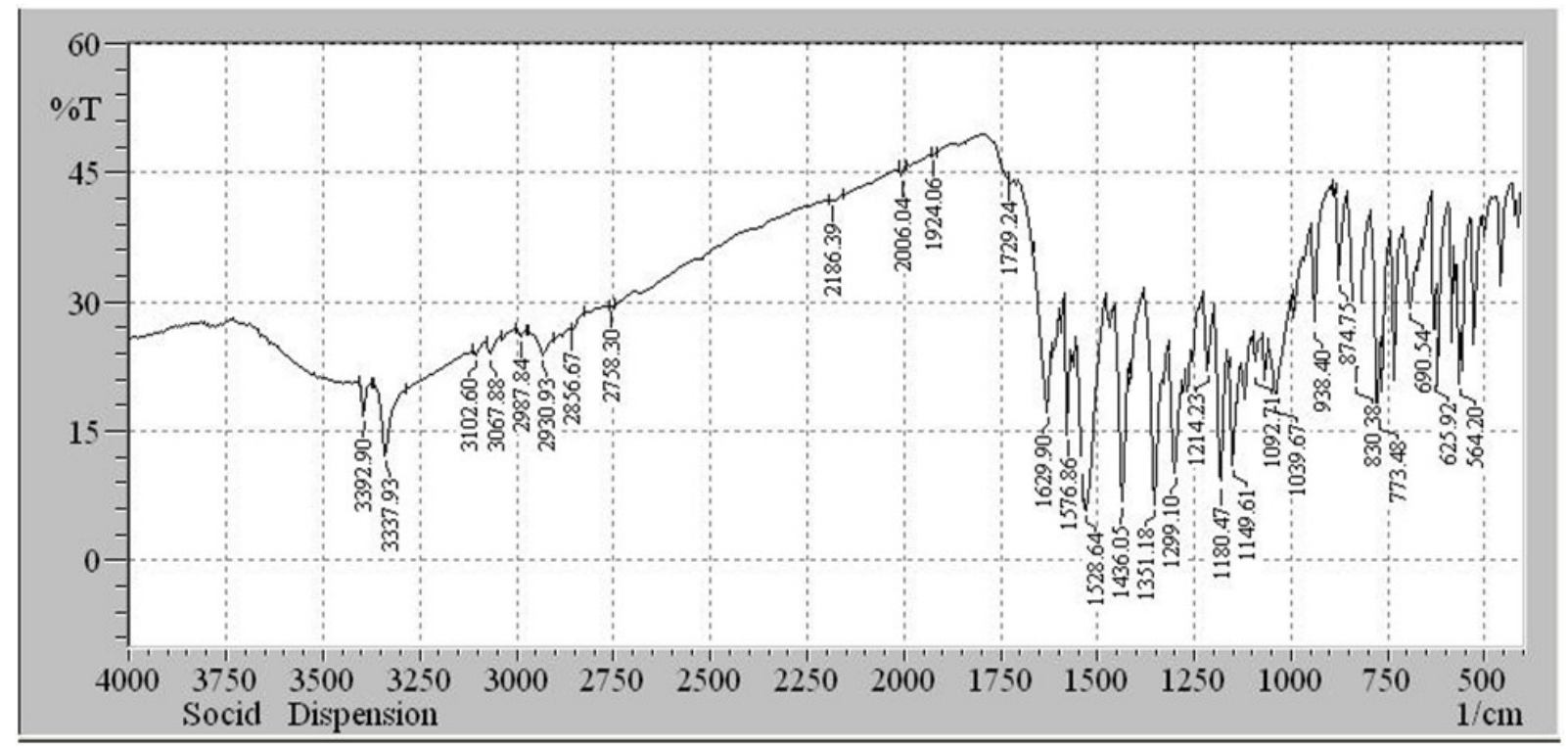

Figure 1: FTIR Study of Solid Dispersion

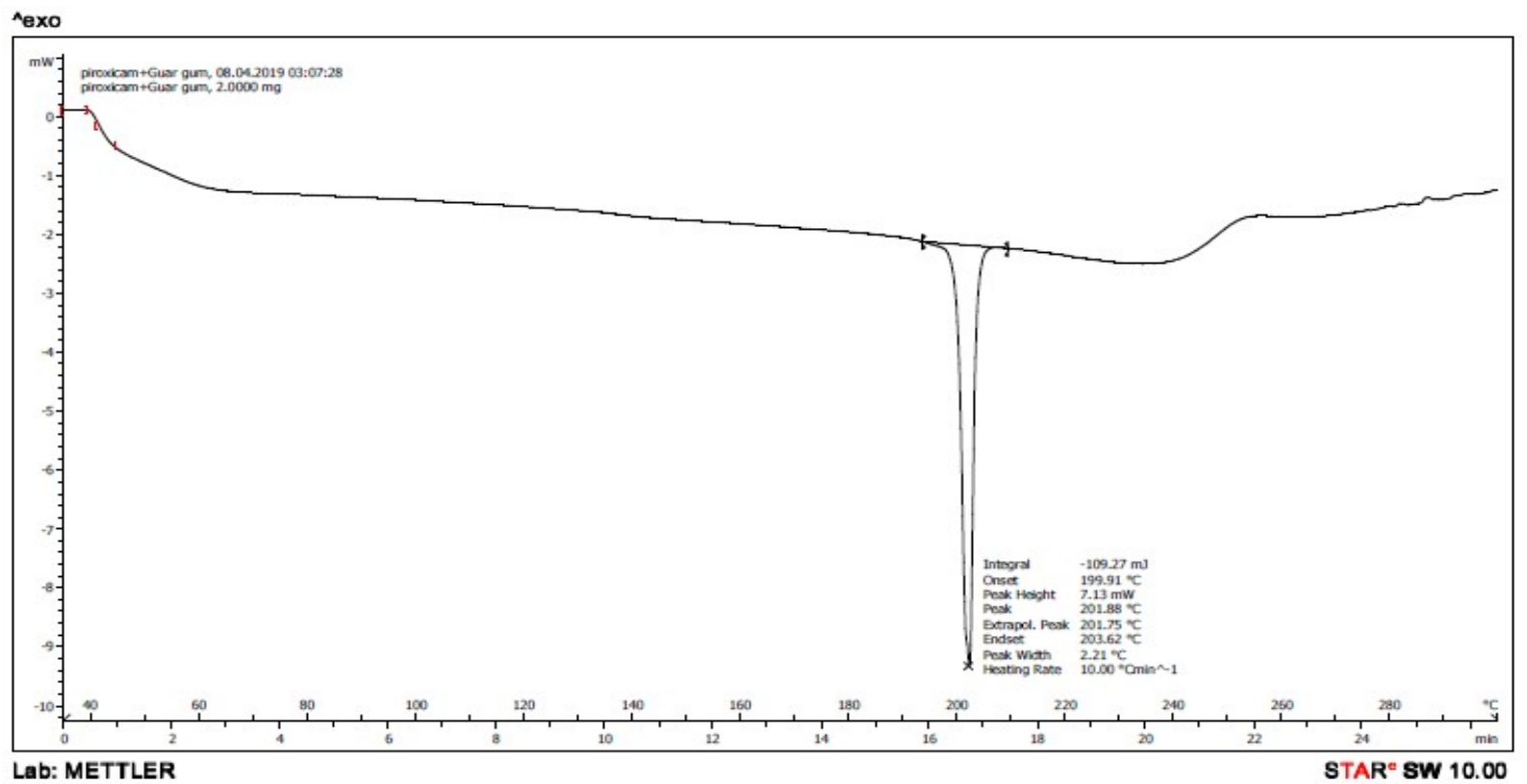

Figure 2: DSC Study of Solid Dispersion

Table 2: Solubility Study of Solid Dispersion batches

\begin{tabular}{|c|c|}
\hline $\begin{array}{c}\text { Ratio of Piroxicam }+ \\
\text { Guar Gum }\end{array}$ & $\begin{array}{c}\text { Solubility by kneading Method } \\
(\mathrm{mg} / \mathrm{mL})\end{array}$ \\
\hline $1: 1$ & $\mathbf{0 . 2 8 3} \pm \mathbf{0 . 1 0}$ \\
\hline $1: 2$ & $\mathbf{0 . 2 9 5} \pm \mathbf{0 . 0 6}$ \\
\hline $1: 3$ & $\mathbf{0 . 3 0 2} \pm 0.05$ \\
\hline $1: 4$ & $\mathbf{0 . 3 1 1} \pm 0.09$ \\
\hline $1: 5$ & $\mathbf{0 . 3 1 9} \pm \mathbf{0 . 0 2}$ \\
\hline
\end{tabular}


Table 3: Drug Content Study of Solid Dispersion batches

\begin{tabular}{|c|c|}
\hline $\begin{array}{c}\text { Ratio of Piroxicam }+ \\
\text { Guar Gum }\end{array}$ & Drug Content \\
\hline $1: 1$ & $97.65 \pm 2.37$ \\
\hline $1: 2$ & $98.13 \pm 3.54$ \\
\hline $1: 3$ & $97.31 \pm 2.98$ \\
\hline $1: 4$ & $98.34 \pm 3.66$ \\
\hline $1: 5$ & $98.76 \pm 2.14$ \\
\hline
\end{tabular}

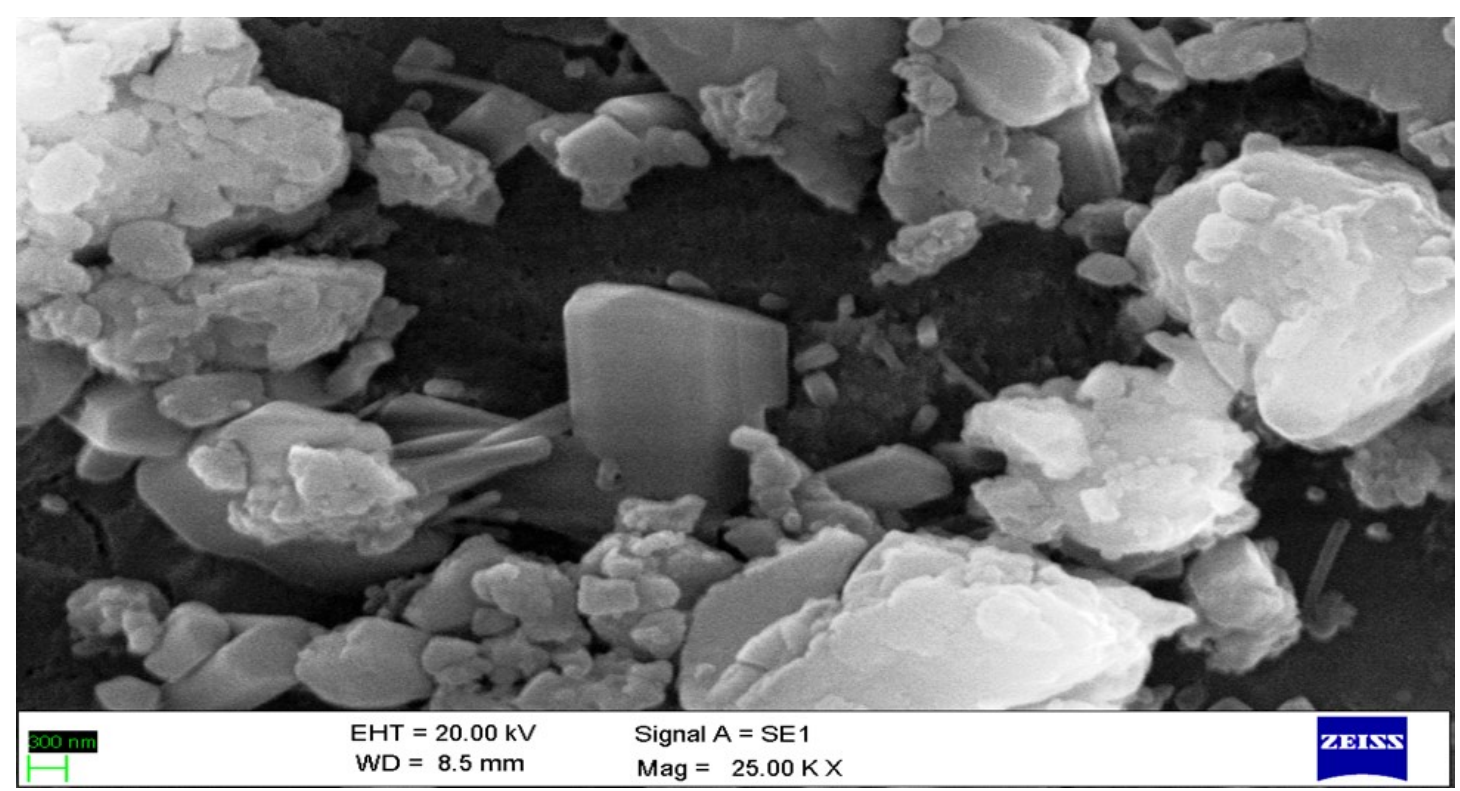

Figure 3: SEM Result of Solid Dispersion

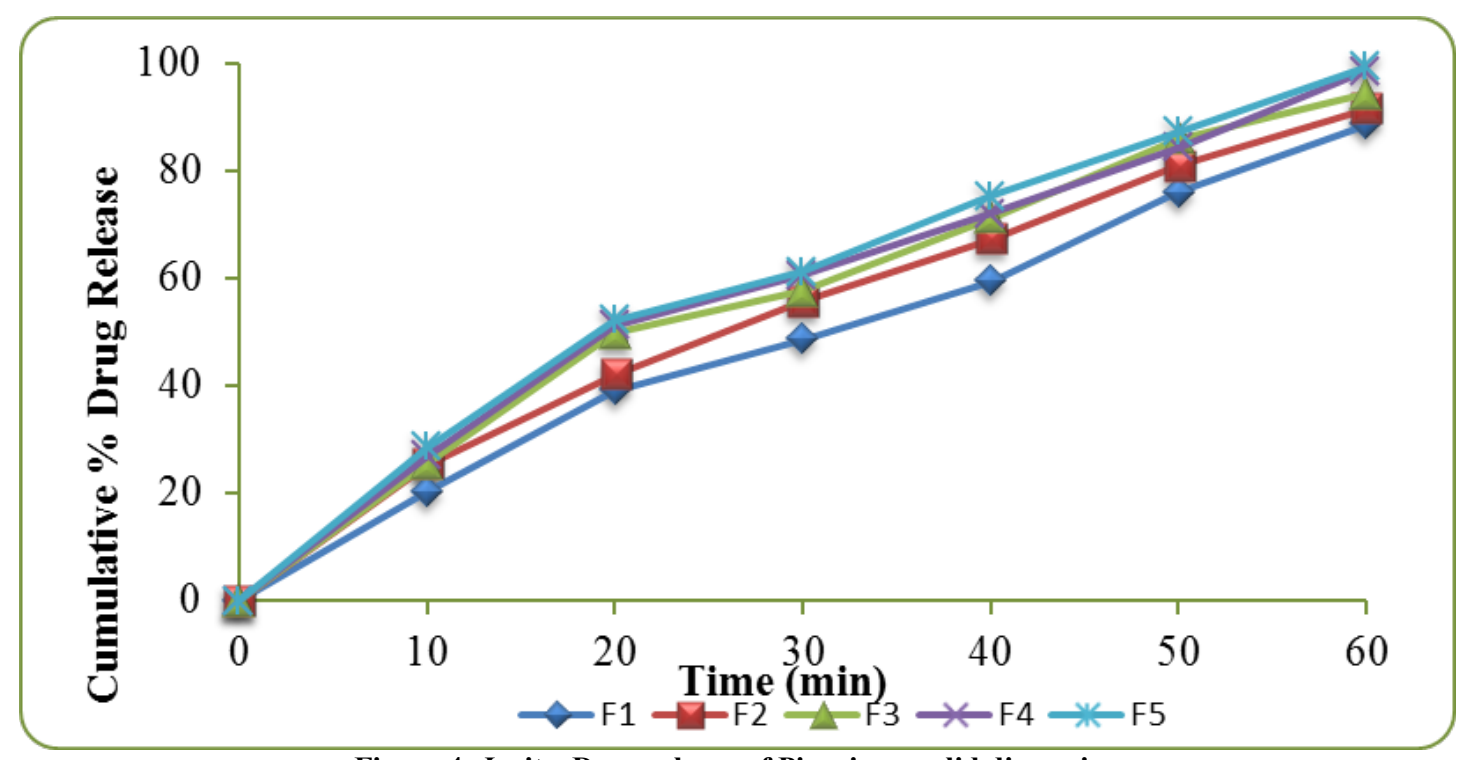

Figure 4: InvitroDrug release of Piroxicam solid dispersion 


\section{CONCLUSION}

The aim \& objectives of the present research work is enhancement of solubility and dissolution of poor water soluble drug Piroxicam. The Solid Dispersion of Piroxicam was prepared using various different ratio of Guar Gum from batches F1 to $F 5$ at ratio of $1: 1$ to $1: 5$. The properties of solid were evaluated using FTIR spectroscopy, DSC, SEM, Drug, content solubility and dissolution studies. SEM result showed that Piroxicam was dispersed and was present as amorphous state in the solid dispersions. Soubiity of solid dispersion of F5 batch at ratio of $1: 5 \quad 0.319 \pm 0.02$ $(\mathrm{mg} / \mathrm{mL})$. The drug release data of solid dispersion revealed that formulation F5 exhibited more than $95 \%$ drug release after $60 \mathrm{~min}$ so increase in dissolution is seen. The results shown best in batch F5 because in which more amount of selected carrier Guar gum have sufficient Solubility, Drug content, Invitro drug released and SEM study. The use of Guar gum to enhance the solubility and increase the dissolution rate of Piroxicam has been observed since Guar gum is reducing the particle aggregation and increase the Wettability and formation of amorphous solid dispersion.

Finally we conclude that the solubility enhancement is depend on nature and amount of the carrier and when increases the carrier increase the solubility of Piroxicam. Solid dispersion system of Piroxicam and carriers used could improve the solubility and dissolution rate of various other drugs.

\section{ACKNOWLEDGEMENT}

The authors are thankful To Hazrat G.M. Vastanvi, President of Ali Allana College of Pharmacy Akkalkuwa for providing the research facilities, Shree Swami Samarth Ayurvedic Pharmacy, Jalgaon for gift samples of Piroxicam,Maliba college of Pharmacy Bardoli Dist.Surat for FTIR Study, \& R.C.Patel college of Pharmacy Shirpur for DSC Study and Divya Lab Mumbai for SEM Study.

\section{REFERENCES}

[1] Al Sheyyab RY, Obaidat RM, Altall YR, Abuhuwaij RT, Ghanma RR, Ailabouni AS, Mashaqbeh HA, AlHaj S. Solubility enhancement of Nimodipine through preparation of Soluplus ${ }^{\circledR}$ dispersions. Journal of Applied Pharmaceutical Science. 2019; 9(09): 30-7.

[2] Swain R.P., Subudhi B.B., Amorphous solid dispersions of Pioglitazone Hydrochloride using Cremophor rh 40 and Poloxamer 188: 
In vitro and in vivo evaluation. Indian Drugs.2019,.56(1):45-55.

[3] Mohammad A. Altamimi., Ehab M. Elzayat., Wajhul Qamar., Sultan M. Alshehri., Abdelrahman Y. Sherif.,Nazrul Haq., Faiyaz Shakeel., Evaluation of the bioavailability of hydrocortisone when prepared as solid dispersion. Saudi Pharm J. 2019, 27: 629-636.

[4] Preparation and pharmacokinetic evaluation of Curcumin solid dispersion using Solutol (R) HS15 as a carrier, Int. J. Pharm. 2012,15: 1825.

[5] Febriyenti F., Rahmi S., Halim A., Study of Gliclazide solid dispersion system using PVP K-30 and PEG 6000 by solvent method. J.Pharm Bio. Sci. 2019, 11(3): 262-267.

[6] Pekamwar S.S., Kankudte A.D., Kale G.K., formulation and evaluation of solid dispersion of lopinavir by using different technique. Int. J. Pharm. 2015, 6(9): 663-669.

[7] Tagalpallewar V R., Ughade M A., Indurwade $\mathrm{N} \mathrm{H}$, Enhancement of Solubility of poorly water soluble drug by solid dispersion technique. Int. J. Pharm. Sci. Res. 2015, 6 (2): 352-361.
[8] Sapkal S B., Shinde S A., Darakhe R A., Shrikhande V N.,Solid dispersion of valsartan for solubility improvement. World. J. Pharm. Sci. 2018, 7(5): 1863-1883.

[9] Kaja R., Raju Y P., Nagaraju R., Dissolution enhancement of valsartan using natural polymers by solid dispersion technique. Scholar. Res. Library. 2013, 5 (2): 126-134.

[10] Amar G., Kamthane B M., Birajdar A S., formulation development and evaluation of Orodispersible tablet of Piroxicam using sodium alginate as a superdisintegrant. Int. J. Pharm. Sci. Res. 2012; 4(6): 7-17.

[11] Palanichamy S., Kiran N R., Rajesh M., $\quad \mathrm{S}$ and A., Formulation development and evaluation of Piroxicam Orodispersible tablets using different superdisintegrants. Der. Pharma. Letter. 2011, 3(4): 155-162.

[12] Sinha S., Ali M., Baboota S., Ahuja A., Kumar A., Ali J., Solid Dispersion as an Approach for Bioavailability Enhancement of Poorly Water-Soluble Drug Ritonavir. The AAP J. 2010, 11 (2): 518-527 
[13] Formulation, Evaluation and Characterization of Solid Dispersions of Pioglitazone Hydrochloride, Indian J. Pharm. Educ. Res. 2013, 47(2): 113-122

[14] Shaik N B., Toleti M., Kanaru D., Kukati L., Solubility Enhancement of Aceclofenac by Solid Dispersion. American J. Pharm Res. 2018, 8(3): 108-130.

[15] Bhaskar R, Monika OLA, Ravindra M. Ghongade. Review: Solid Dispersion Technique for Enhancement of Solubility of Poorly Soluble Drug. Indian J. Pharm. Bio Res. 2018, 6(2): 43-52. 